This item was submitted to Loughborough's Research Repository by the author.

Items in Figshare are protected by copyright, with all rights reserved, unless otherwise indicated.

\title{
Membrane emulsification: droplet size and uniformity in the absence of surface shear
}

PLEASE CITE THE PUBLISHED VERSION

http://dx.doi.org/10.1016/j.memsei.2008.01.009

PUBLISHER

(C) Elsevier

VERSION

AM (Accepted Manuscript)

LICENCE

CC BY-NC-ND 4.0

\section{REPOSITORY RECORD}

Kosvintsev, S.R., G. Gasparini, and R.G. Holdich. 2012. "Membrane Emulsification: Droplet Size and Uniformity in the Absence of Surface Shear". figshare. https://hdl.handle.net/2134/9306. 
This item was submitted to Loughborough's Institutional Repository (https://dspace.lboro.ac.uk/) by the author and is made available under the following Creative Commons Licence conditions.

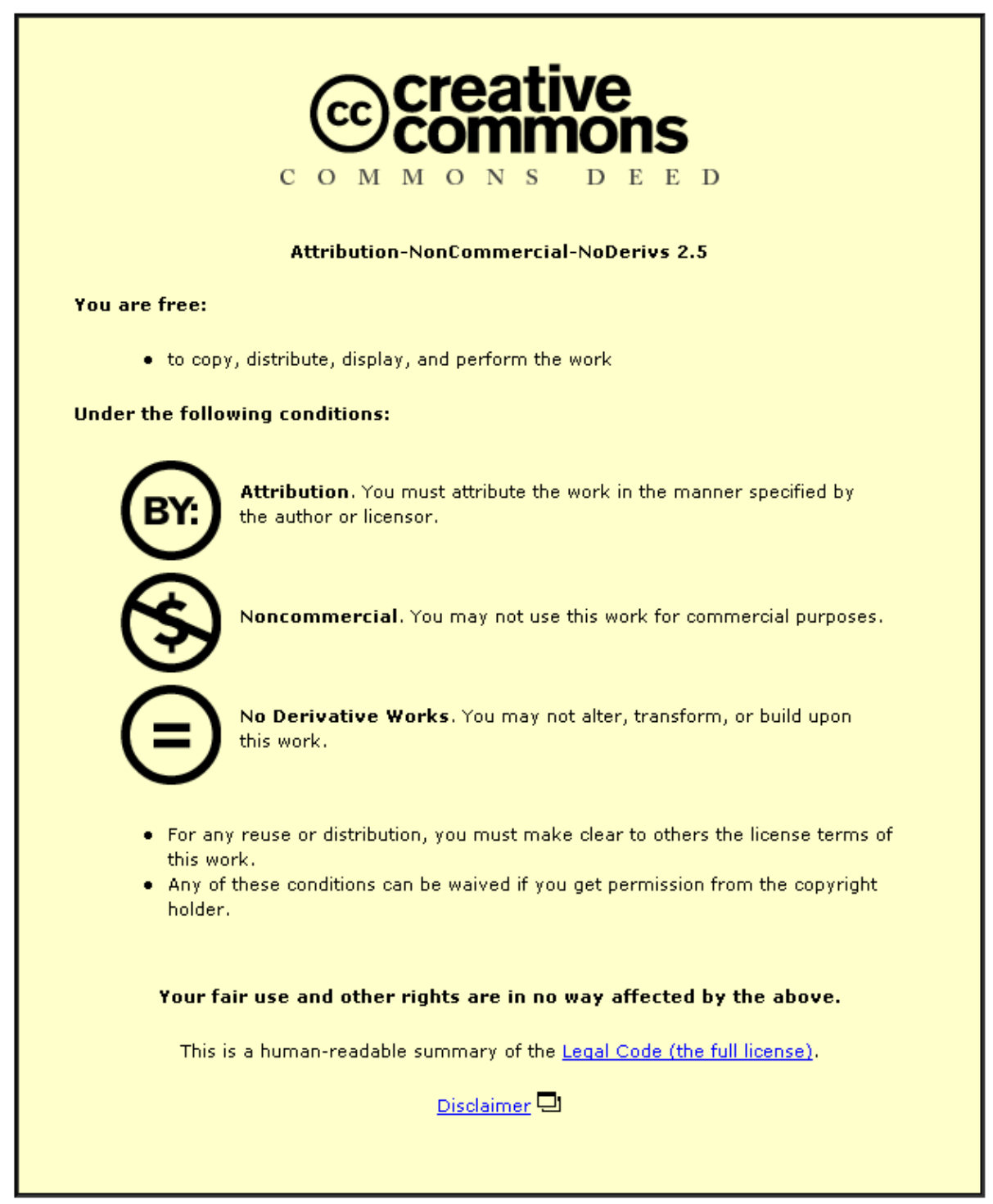

For the full text of this licence, please go to: http://creativecommons.org/licenses/by-nc-nd/2.5/ 


\title{
Membrane Emulsification: Droplet Size and Uniformity in the Absence of
}

\section{Surface Shear}

\author{
Serguei R. Kosvintsev ${ }^{1}$, Gilda Gasparini ${ }^{2}$ and Richard G. Holdich ${ }^{2 *}$ \\ ${ }^{1}$ Micropore Technologies LTD, Epinal Way, Loughborough, Leics., LE11 3EH. \\ ${ }^{2}$ Department of Chemical Engineering, Loughborough University, \\ Leicestershire, LE11 3TU, U.K.
}

\begin{abstract}
A series of tests with membrane pore sizes between 7 and 60 microns and uniform spacing between the pores of 80 and 200 microns, conducted under conditions of zero surface shear at the membrane, show that an additional force to the buoyancy and capillary forces exists in membrane emulsification. A push-off force, derived by consideration of the geometry of the drops as they deform at the surface of the pores under high injection rates when most of the pores are passing liquid, is shown to model the size of the drops formed in the emulsification. In the tests, sunflower oil was injected into water and as the emulsification injection rate increased it was noticeable that there was a point at which the resulting drop distribution is at its narrowest. For the two pore spacings studied: 80 and 200 microns, the point at which the distribution was at its narrowest was at a Weber number of $1.5 \times 10^{-2}$, where the Weber number is defined using the drop diameter rather than the pore diameter.
\end{abstract}

keywords

emulsification, sieve-membrane, force balance, push-off force

*corresponding author's address:

Professor Richard Holdich, Department of Chemical Engineering, Loughborough University, Loughborough, Leicestershire, LE11 3TU, UK. Tel: +44 1509 222519, Fax: +44 1509 223923, e-mail: r.g.holdich@Lboro.ac.uk 


\section{Introduction}

Membrane emulsification is a process to produce an emulsion, or dispersion, of one liquid phase (such as oil) in a second immiscible liquid phase (such as water). The process usually employs shear at the surface of the membrane in order to detach the dispersed phase liquid drops from the membrane surface, after which they become dispersed in the immiscible continuous phase. In many cases the liquid drops are then polymerised, or otherwise solidified, in order to produce solid particles, usually with a very narrow particle size distribution. Examples of such products include: calibration materials, food and flavour encapsulates, controlled release depots under the skin, ion exchange resins, etc [1].

High surface shear at the membrane surface is appropriate to the formation of fine dispersions and emulsions $[2,3,4,5,6]$, but low surface shear, or none at all, is appropriate to the formation of larger liquid drops [7]. In the absence of surface shear, the force to detach the drop from the membrane surface is usually believed to be buoyancy, which counteracts the capillary force - the force retaining the drop at the membrane surface. However, there is observational evidence, and a previously reported study [8], to suggest that there is an additional force causing detachment from the membrane pores, this force is applicable when there are a large number of drops at the membrane surface - causing drops to deform from their preferred spherical shape. This force is known as the push-to-detach, or push-off, force and is investigated further in this study.

In previous studies $[9,10]$ a stirred cell was described in which membrane emulsification could be achieved using a circular disc membrane of the type 
illustrated in Figure 1, on top of which a simple paddle blade stirrer induced shear at the membrane surface, resulting in droplet detachment during membrane emulsification. A stirred cell for membrane emulsification is an unusual device to use when a uniform drop distribution is required. Most processes use crossflow or, for the generation of larger diameter drops, microchannels [11] or a rotating tubular membrane in a stationary liquid [7]. It is commonly believed that a uniform shear field is required for the generation of monosized drops by membrane emulsification, hence devices that provide a uniform shear field at the surface of the membrane are suggested. However, in the previous study [10], it was found that a simple paddle stirrer, with a consequently varying radial shear field at the surface of the membrane, could produce drops of an oil phase dispersed in a low viscosity water phase with a high degree of homogeneity. The membrane pore diameter used in the previous study was $20 \mu \mathrm{m}$ and drops with diameters between 40 and $110 \mu \mathrm{m}$ were produced. The mean size varied as a function of the stirrer speed and, hence, shear imposed at the membrane surface. However, it was noted that the force balance model overestimated the drop size produced by the system when operating at low shear rates at the membrane surface and high injection rates of dispersed phase. In other words, there appeared to be an additional force acting to detach the drops off the surface of the membrane, which is dominant at values of low shear and high injection rate.

In the absence of shear flow at the membrane surface, the size of the drop in emulsification may be defined by the buoyancy force. If the buoyancy force is directed towards the membrane, or difference in density of discontinuous and continuous phases is small, apparently, there is no reason for a drop to stop growing. However, in membrane emulsification thousands, or hundreds of thousands, of pores 
are generating drops simultaneously. Drops grow from the holes under the applied pressure of the injecting fluid. As shown by Nisisako [12], Xu [13] and Van Der Graaf [14], the formation of a neck leads to conditions which favour detachment, see Figure 2. In the condition of a regular array membrane, similar to that shown in Figure 1, if the drop diameter is bigger than the distance between the pores, then the drop shape deviates from spherical towards a prolate spheroid at high injection rates. Similar behaviour is visible in [8]. If the inter-pore distance is large and the surfactant stabiliser acts fast enough, the drops do not coalescence. At the early stage of drop formation, the drop surface interface area increases rapidly. The interfacial energy therefore changes as the drops grow. If the surfactant has sufficient time to stabilise the interface so that the drops do not coalesce, then the drops at adjoining pores on the membrane surface will be stable and act as deforming particles. This deformation leads to additional work done in the system: the capillary force retains the drops at the membrane surface in what would otherwise be a minimum energetic state, i.e. spherical drops. Hence, for dispersed drop size modelling, and understanding, there is an additional force due to the presence of neighbouring drops, which deform the drops from their otherwise spherical and minimum energy state and gives rise to a push-off force after which the drops achieve their minimum energy state when they return to a spherical shape, after detachment. In a highly regular membrane, such as that illustrated in Figure 1, it may be that the presence of this additional force helps to produce more uniformly sized drops.

There are many ways that the degree of narrowness of the size distribution can be reported, such as: variance, sharpness of distribution, standard deviation, but for the 
sake of simplicity the method employed here will be a commonly used one by commercial laser light diffraction apparatus, which is the span defined as

$$
\operatorname{Span}=\frac{D_{90}-D_{10}}{D_{50}}
$$

where $D_{90}, D_{50}$ and $D_{10}$ are the particle sizes at which 90,50 and $10 \%$ of the distribution lies below on a cumulative undersize figure. Span values of less than 1 are usually deemed to show monosized distributions [6].

\section{Dispersed Drop Size Modelling}

The push-off mechanism is likely to be more noticeable with a regular array membrane, such as that illustrated in Figure 1, compared to membrane emulsifications using conventional membranes such as the Shirasu Porous Glass (SPG) type. The latter is an irregular array of pores where the pore openings are randomly spaced on the membrane surface. Studies using the SPG membrane have suggested that the surface utilisation of this type of membrane may be as low as $1 \%$, but with increasing injection rate this utilisation increases [15]. The low utilisation of the membrane surface area is due to the irregular and tortuous pore channels in this type of membrane, whereas the regular array type of membrane illustrated in Figure 1 has very uniform pores and pore channel depth. It is likely that the rate of membrane utilisation is significantly greater than with the SPG type of membranes. If the drops are allowed to grow in the absence of shear a consideration of the energy of the system suggests that it is likely that drops of a more uniform size will be formed, as within a size range of drops the bigger drops will have a higher surface area and, hence, a bigger overall energy requirement. However, for the push-off mechanism to 
exist it is important to ensure that jetting of the injected liquid into the continuous phase does not occur.

The process of membrane emulsification uses the membrane to control the drop size of the emulsion formed, if the rate of injection of dispersed phase in to the continuous phase is too great a jet of dispersed phase will form at the pore and drop formation will be due to drop instability. This will lead to a large drop size distribution and is not the best use of the membrane for membrane emulsification; i.e. the intention is to not use the jetting regime for the production of the drops. Hence, there is a limit to the rate of injection, it needs to be below the jetting regime. These can be assessed by consideration of the dimensionless numbers appropriate to the process, given below

$$
\mathrm{Re}=\frac{2 r_{p} \rho v}{\mu} ; \mathrm{Ca}=\frac{\mu v}{\gamma} ; \mathrm{We}=\frac{r_{p} \rho v^{2}}{\gamma} ; \mathrm{We}_{\mathrm{p}}=\frac{D(n, 0.5) \rho v^{2}}{\gamma}
$$

where $\mathrm{Re}$ is drop Reynolds number, $\mathrm{Ca}$ is the capillary number, We is the Weber number, $\rho$ is the liquid density, $D(\mathrm{n}, 0.5)$ is the median size of the drops on a number size distribution, $v$ is the velocity of the injected liquid through a pore, $\mu$ is the coefficient of dynamic viscosity, $\gamma$ is the interfacial tension, and $r_{\mathrm{p}}$ is the radius of the pore channel. A small Capillary number indicates that the capillary force (interfacial tension) prevails over the viscous dissipation force and push-off may be valid. The Weber number (We) is defined in the conventional manner, by pore radius, and when it is small it indicates that the inertial force is negligible compared with the interfacial force. However, it may be more appropriate to consider a definition of the Weber number based on the diameter of the drops formed, rather than the much smaller pore orifice diameter, as the phenomenon under investigation is the stability of a column of liquid, or jet, above the membrane pore which would otherwise have a diameter equal 
to the formed drops. This is termed the particle Weber number $\left(\mathrm{We}_{\mathrm{p}}\right)$. In the study reported here, the membrane is a very thin lamina metal sheet and, clearly, flow will not have time to develop through the membrane channel. Hence, the Reynolds and Capillary numbers are only indicative values - to illustrate the minimal effect of inertia relative to viscous forces (low $\mathrm{Re}$ ) and the minimal effect of the viscous force relative to interfacial tension (low $\mathrm{Ca}$ ). Hence, the system under investigation is dominated by the interfacial tension and whatever force is shown later to cause the drops to detach from the membrane.

The logic behind the push-off force comes from a consideration of an energy balance of the emerging drops, an approach that has been suggested previously and solved using a numerical technique based on the surface evolver software[16]. In this previous work the energy of a single emerging drop was considered and determined for the situation when it was more energetically favourable for the drop to exist as a separate drop detached from the membrane. An alternative approach is adopted in this paper, which is to develop an analytical equation for the drop diameter of the spherical drop formed after detachment; where that detachment is in part due to the presence of other drops and then to solve the equation iteratively using a standard mathematical package. The essence of the model is that work done on the system goes in to increasing the interfacial area between the emerging drops and the continuous phase, Figure 2, until the force on the drops to provide this work done is sufficient to overcome the capillary force holding the drops to the membrane opening. Each drop is surrounded by four neighbours, which exert a force on the central emerging drop causing it to deform. Hence, if the force exerted by each neighbour is $F_{\mathrm{OFF}}$

$$
4 F_{O F F} d x=\gamma d A
$$


where $\mathrm{d} x$ is the distance along the path of the force, $\gamma$ is the interfacial tension and $\mathrm{d} A$ is the change in area, which at the point of interest will be the change in area due to the formation of an ellipsoid rather than a spherical drop. The point of interest being the spherical drop size at which the drop detaches from the membrane, as this will be the drop size of the formed emulsion. However, this will be different from the diameter of the ellipsoid formed on the membrane surface, as this will be smaller than the spherical drop size, which is measured after detachment. Hence, it will be necessary to relate the spherical drop diameter, which is measured, and the ellipsoid drop diameter formed at the membrane surface.

The pressure inside a deformed drop will be uniform, as a consequence of Pascal's principle (also illustrated in Figure 2), hence it is possible to write a force balance between the capillary force attaching the drops to the membrane pore and a net detachment force $(G)$, arising from the push-off, deemed to be operating in the vertical direction and causing the drops to detach, see Figure 2. Hence,

$$
G d z=4 F_{O F F} d x=\gamma d A
$$

where $\mathrm{d} z$ is the deformation of the ellipsoid, from a sphere, in the vertical direction. The modelling approach depends on predicting the area increase due to the deforming drop. Using conservation of mass to determine the change in area, $\Delta A$ provided by equation (2), the change in area due to the deforming drop is

$$
\Delta A=\left(S_{e l l}-S_{s p h}\right)
$$

The surface area of a sphere is

$$
S_{s p h}=\pi D^{2}
$$

The surface area of an ellipsoid is 
$S_{\text {ell }}=\frac{\pi}{2} L\left(L+\frac{D_{\text {ell }}^{2} \arcsin \left(\frac{\sqrt{D_{\text {ell }}^{2}-L^{2}}}{D_{\text {ell }}}\right)}{\sqrt{D_{\text {ell }}^{2}-L^{2}}}\right)$

Considering the volumes of a sphere and ellipsoid, the equation relating the diameter of an ellipsoid to the diameter of a sphere of equal volume is

$D_{\text {ell }}=\frac{D^{3}}{L^{2}}$

When calculating the surface areas, a surface area of the neck should be removed from the entire surface area $S_{\text {ell }}$ in equation (5), see Figure 2 for an illustration of the neck region. However, for drops greater than 100 microns in diameter formed on a membrane with pore diameter of 20 microns the neck area will be insignificant. Hence, it has been neglected for this analysis. Similarly, another force has been proposed due to the action of the static pressure inside and outside of the droplet at the position of the neck: i.e. the force due to static pressure difference [13]. Determination of this force depends on a knowledge of the neck diameter and the drop diameter. In the experimental study shown here the neck diameter will be unknown, but less than the 20 micron pore diameter, and the droplet diameters approach 200 microns. Hence, in the absence of information on the neck, this force has been neglected from the mathematical analysis, which should provide an error of less than $10 \%$ on the final calculated values of forces.

Equations (3), (5) and (6) can be used to provide an equation that relates the difference in surface area between a sphere and ellipsoid, in terms of spherical droplet diameter and pore spacing. The latter term providing the diameter of the ellipsoid in 
the direction parallel to the membrane surface when the drops are deforming at a high concentration at that surface.

$$
\Delta A=\frac{1}{2} \pi\left[L^{2}-2 D^{2}+\frac{D^{6} \arcsin \left(\frac{L^{2} \sqrt{\frac{D^{6}}{L^{4}}-L^{2}}}{D^{3}}\right)}{L \sqrt{D^{6}-L^{6}}}\right]
$$

Using equation (2) to relate $z$, and change in area from equation (7), gives the equation for the push-off force

$$
G=\frac{1}{2} \frac{\gamma \pi D^{3} L \arcsin \left(\frac{\sqrt{D^{6}-L^{6}}}{D^{3}}\right)\left(D^{6}-2 L^{6}\right)}{\left(D^{6}-L^{6}\right)^{3 / 2}}+\frac{\gamma \pi D^{2} L^{7}}{2\left(D^{6}-L^{6}\right) \sqrt{\frac{L^{6}}{D^{2}}}}-\frac{2 \gamma \pi L^{2}}{3 D}
$$

In equation (8) the push-off force is related to the volume of the drops, or the equivalent spherical diameter of the spherical drops formed $D$, and the distance between the pores $(L)$. The latter dependency is shown in Figure 3. In this case, the volume of drop was fixed with four values corresponding to drop diameters 500, 400 300, and 200 microns, and the clearance between centres of the drops is investigated.

This dependency shows that, at the fixed drop diameter, the push-off force grows with decreasing the distance between pores, and reaches a maximum when the distance between the pores is about 0.55 times less then drop diameter. When $L$ is close to 
zero, the push-off force vanishes. This is when the drops are very prolate and are, in fact, cylinders.

\section{Critical drop diameter}

The critical drop diameter is the diameter of the spherical drop that will detach from the pore of a membrane of given distance between the pore centres. The force retaining the drop to the surface pore of the membrane is the capillary force

$$
F_{c a}=2 \pi \gamma r_{p}
$$

The forces that may detach the drop are buoyancy and push-off forces. The buoyancy force is important for large drop sizes. The equilibrium condition for the buoyancy of a single drop, without significant push-off force (i.e. $L$ much greater than $D$ ) is

$$
F_{b}=\frac{1}{6} \pi g D^{3}\left(\rho-\rho_{\text {oil }}\right)
$$

Hence, for the buoyancy force to be the dominant detachment mechanism, the drop size should be

$$
D \approx \sqrt[3]{\frac{12 \gamma r_{p}}{g\left(\rho-\rho_{o i l}\right)}}
$$

For the system investigated with an interfacial tension of $7 \mathrm{mN} \mathrm{m}^{-1}$, pore radius of $1 \times 10^{-5} \mathrm{~m}$, and density difference of $140 \mathrm{~kg} \mathrm{~m}^{-3}$ the drop diameter should be bigger than $1.3 \times 10^{-3} \mathrm{~m}$, or 1300 microns in the absence of a push-off force. This is a very large drop size. 
Equations (8), (9) and (10) can be solved for the spherical drop diameter under the condition when the capillary force is balanced by both the push-off and buoyancy forces

$F_{c a}=F_{b}+G$

This provides the critical drop diameter. The equation has to be iteratively solved and this has been achieved using Maple 9. The results of a calculation are presented in Figure 4 as a function of pore size for the two different values of spacing between the membrane pores used in the experimental study: 80 and 200 microns, and the physical characteristics of the liquids used in the experiments.

\section{Experimental}

The emulsion was obtained by a membrane technique using a flat, circular metal hydrophilic membrane with an array of uniform pores. Different pore sizes and pore distances were tested. The discontinuous phase was made of pure sunflower oil (food grade from a local supermarket). The continuous phase was composed of $2 \%$ Tween 20 (Acros Organics) in reverse osmosis water (obtained from a Millipore RO unit). The membrane emulsification apparatus, a Dispersion Cell, was provided by Micropore Technologies Ltd, Leicestershire, UK. A total of $15 \mathrm{ml}$ of discontinuous phase was injected through the membrane into $150 \mathrm{ml}$ of continuous phase for each test. The injection was performed using a syringe pump. Once the desired amount of discontinuous phase was pushed through the membrane, the pump was switched off, the droplets were allowed to float, and then removed for analysis. The obtained droplet diameter and size distribution was measured by laser diffraction, using a 
Malvern Mastersizer. Interfacial tension measurements were made using the Du Nouy ring method, White Elec. Inst Co Ltd model DB2KS. In most respects, the equipment and procedures were similar to what was reported previously [9], but without the application of shear at the membrane surface.

\section{Results \& Discussion}

\section{Injection rate dependency}

The push-off force is connected with some collective motion of the drops when, ideally, all the pores on the membrane surface are working. It is assumed that this corresponds to the same injection rate through all the membrane pores participating in the emulsification. In one limiting case, when only a few of the pores are working, and distance between those pores is bigger than the size of the drops, the push off force is zero and final drop size is defined only by an equilibrium of buoyancy and capillary forces.

At increasing injection rate, more and more pores will pass injected liquid [15] and the push-off force becomes significant. Hence, the size of the drops becomes defined by the push-off force and, possibly, the buoyancy force. The particle size distributions corresponding to the different injection rates (from 0.1 up to $30 \mathrm{ml} / \mathrm{min}$ ) are presented, as determined by laser diffraction, in Figure 5 for the tests using a 20 micron pore sized membrane. From each distribution three parameters $\mathrm{D}(\mathrm{n}, 0.1), \mathrm{D}(\mathrm{n} 0.5)$, and $D(n, 0.9)$ were obtained and those parameters are plotted as a function of the injection rate in Figures 6 and 7. 
In Figure 6 the region between the displayed bars indicate $80 \%$ of the drop size distributions i.e. the lower limit corresponds to $\mathrm{D}(\mathrm{n}, 0.1)$, and the upper is $\mathrm{D}(\mathrm{n}, 0.9)$, the experimental markers are at $\mathrm{D}(\mathrm{n}, 0.5)$. Figure 7 provides a similar plot for a membrane with the same pore size, but spacing between the membrane pores of 200 microns.

It is noticeable, see Figure 5, that there is some range of injection rate where emulsification gives the most monosized drop distributions. For very small injection rates the drop size distribution is very broad and bi-modal. The very small drops lower the value of $\mathrm{D}(\mathrm{n}, 0.5)$ in a number distribution and for $0.5 \mathrm{ml} / \mathrm{min}$ very big drops $(600$ microns) are formed as well. This indicates that for small injection rates the emulsification is not stable: satellite drops appear to form together with drops defined in size by equilibrium of buoyancy and capillary forces (up to 1300 microns), which may well then become broken in the emulsification cell, or on sampling.

At just below $10 \mathrm{ml} / \mathrm{min}$ the membrane emulsification gives the best distribution with the lowest span. For bigger values of injection rate the distribution again becomes worse. At injection rates greater then $20 \mathrm{ml} / \mathrm{min}$ very big drops (up to $0.5 \mathrm{~cm}$ ) were formed in the centre of the membrane. These drops were not detected by the analytical equipment, due to buoyancy, as they did not enter the detection cell. The increasing size, and widening, of the distribution occurs most probably because jet instability forms. Table 1 provides data for the dimensionless numbers provided earlier. For all the injection rates the Reynolds and Capillary numbers are very small. There is no evidence in Figures 6 and 7 to suggest that the drop size increases with injection rate, or Capillary number, after a threshold value, as has been found previously in microchannel emulsification [17]. In that work, a critical Capillary number of 0.052 
was determined as the threshold between drop diameters remaining stable, as a function of injection rate, and beyond that threshold where average diameters were observed to increase with injection rate. It is noticeable that all the Capillary numbers reported in Table 1 are below the suggested threshold of 0.052 . Hence, the work reported here is consistent with the conclusions from the microchannel study, but in this work the higher injection rates appear to suffer from a broader drop size distribution.

Figures 6 and 7 illustrate the existence of an optimum injection rate at which there appears to be the most uniform drop size distribution formed: $8 \mathrm{ml} / \mathrm{min}$ for the 80 micron clearance membrane and nearly $10 \mathrm{ml} / \mathrm{min}$ for the 200 micron clearance membrane. Either side of this optimum injection rate the range between the D90 and D10 is greater, giving rise to an apparent butterfly-plot shape to the curve. It is hypothesized that at this optimum injection rate the drops touch each other and the push-off force is working to form consistent drops at the membrane surface. Beyond this injection rate some form of instability is apparent, leading to a wider size distribution.

Figures 8 and 9 illustrate data for a variety of membrane pore sizes using the two different pore spacings of 80 and 200 microns. The span is plotted against the Weber number, based on the drop diameter rather than the pore diameter. For both pore spacings, and for all the membrane pore sizes, there is a minimum span value, i.e. most monosized distribution, at a Weber number close to $1.5 \times 10^{-2}$. This appears to be the optimum conditions to operate the emulsification, in the absence of surface shear, if the objective is to have a narrowly size distributed product. 
In Figure 10 the predicted average drop diameters, from equation (12), are compared with the measured values for the different pore sized membranes at both 80 and 200 micron pore spacing. There are three theoretical curves: a solution based on buoyancy and capillary forces, neglecting the push-off force which gives the same curve for both 80 and 200 micron pore spacing, and two separate curves for the solution to equation (12) taking account of the push-off force for the two separate pore spacings. On the same figure experimental data is displayed for tests using membrane pore sizes between 7 and 60 microns, and the two different pore spacings. The experimental markers are the median number distribution values and the bars represent the distance between the D90 and D10 of the distributions. The agreement between the predicted and measured data appears to be good for the model that includes the push-off force. Clearly, a model based solely on buoyancy does not represent the data.

\section{Conclusions}

Using a series of membranes with a highly uniform pore spacing of 80 and 200 microns, and uniform pore sizes between 7 and 60 microns, under conditions of zero surface shear at the membrane, it has been shown that an additional force to the buoyancy and capillary forces exists in membrane emulsification. Modelling of the emulsification process using buoyancy as the sole force causing detachment from the membrane surface provides results considerably in error when compared to the experimental data. Adding a push-off force, derived by consideration of the geometry of the drops as they deform at the surface of the pores, provides good agreement between the model and data. The push-off force is the dominant detachment force in the force balance. However, the push-off force only becomes significant at 
emulsification injection rates sufficient for an array of drops to appear at the membrane surface. The force depends upon adjacent drops at the pore openings interacting with each other, but not coalescing. Under these conditions, the drops will deform from their state of minimum energy, i.e. spherical shape, to that of ellipsoids and a consideration of this deformation gives rise to the mathematical force used to describe the push-off force at the membrane surface, equation (8).

For a given membrane, as the emulsification injection rate is increased it is noticeable that there is a point at which the resulting drop distribution is at its narrowest, i.e. the most monosized drops are formed. Injection rates both lower and higher than this optimal value give a broader drop size distribution. Hence, when plotting the span of the distribution against the injection rate, with markers around the median drop size value at D90 and D10, the figure resembles a butterfly-plot. For the two pore spacings studied: 80 and 200 microns, the point at which the distribution was at its narrowest was at a Weber number of $1.5 \times 10^{-2}$, where the Weber number is defined using the drop diameter rather than the pore diameter. The justification for this approach is that the number is being used to assess the stability of a stream of liquid above the membrane pore which will become unstable at a certain Weber number and the characteristic linear dimension is the stream, or drop, diameter as it comes away from the membrane.

In order to operate a similar, regular pore array, membrane system under conditions where the narrowest drop size distribution is formed equation (12) could be solved to determine the average drop diameter from the experimental conditions, which can then be used to determine the required injection rate to give a Weber number of 
$1.5 \times 10^{-2}$. Hence, from a knowledge of the membrane and physical properties of the liquids, it should be possible to predict the conditions required to provide monosized drops in the absence of shear or other detachment mechanisms apart from buoyancy and push-off forces. 


\section{REFERENCES}

(1) Nakashima, T, Shimizu, M., Kukizaki, M., Particle control of emulsion by membrane emulsification and its applications, Advanced Drug Delivery Reviews, 2000, 45, 47.

(2) Mine, Y. Shimizu, M., Nakashima, T., Preparation and stabilisation of simple and multiple emulsions using a microporous glass membrane, Colloids and Surfaces B, 1996, 6, 261.

(3) Vladisavljevic, G.T. and Williams, R.A., Recent developments in manufacturing emulsions and particulate products using membranes, Adv. Coll. \& Int. Sci., 2005, 113, 1.

(4) Joscelyne, S.M. and Tragardh, G., Membrane emulsification - a literature review, Jnl. Mem. Sci., 2000, 169, 107.

(5) Abrahamse, A.J.G., van der Padt, A., Boom, R.M., Status of cross-flow membrane emulsification and outlook for industrial application, Journal of Membrane Science, 2004, 230, 149.

(6) Williams, R.A., Peng, S.J., Wheeler, D.A., Morley, N.C., Taylor, D., Whalley, M. and Houldsworth, D.W., Controlled production of emulsions using a crossflow membrane Part II: industrial scale manufacture, Trans. IChemE., 1998, 76, 902.

(7) Vladisavljevic, G.T. and Williams, R.A., Manufacture of large uniform droplets using rotating membrane emulsification, Journal of Colloid and Interface Science, 2006, 299, 396.

(8) Zhu, J. and Barrow, D., Analysis of droplet size during cross-flow membrane emulsification using stationary and vibrating micromachined silicon nitride membranes, Journal of Membrane Science, 2005, 261, 136. 
(9) Kosvintsev, S.R., Gasparini, G., Holdich, R.G., Cumming, I.W. and Stillwell, M.T., Liquid-liquid membrane dispersion in a stirred cell with and without controlled shear, Ind Eng Chem Res, 2005, 44, 9323.

(10) Stillwell, M.T., Holdich, R.G., Kosvintsev, S.R., Gasparini, G. and Cumming, I.W., Stirred cell membrane emulsification and factors influencing dispersion drop size and uniformity, Ind Eng Chem Res, 2007, 46, 965-972.

(11) Sugiura, S. Nakajima, M. and Seki, M., Preparation of monodispersed polymeric microspheres over $50 \mu \mathrm{m}$ employing microchannel emulsification, Ind. Eng. Chem. Res., 2002, 41, 4043.

(12) Nisisako, T., Torii, T. and Toshiro, H., Novel microreactors for functional polymer beads, Chemical Engineering Journal, 2004, 101, 23.

(13) Xu, J.H., Luo, G.S., Chen, G.G. and Wang, J.D., Experimental and theoretical approaches on droplet formation from a micrometer screen hole, Journal of Membrane Science, 2005, 266, 121.

(14) van der Graaf, S., Steegmans, M.L.J., van der Sman, R.G.M., Schroen, C.G.P.H. and Boom, R.M., Droplet formation in a T-shaped microchannel junction: a model system for membrane emulsification, Colloids and Surfaces A: Physicochemical and Engineering Aspects, 2005, 266, 106.

(15) Vladisavljevic, G.T., Lambrich, U., Nakajima, M. and Schubert, H., Production of $\mathrm{O} / \mathrm{W}$ emulsions using SPG membranes, ceramic alphaaluminium oxide membranes, microfluidizer and a silicon microchannel plate - a comparative study, Colloids and Surfaces A: Physicochemical and Engineering Aspects, 2004, 232, 199. 
(16) Marilyn, R., Trägardh, G., Trägardh, C. and Dejmek, P., Using the surface evolver to model droplet formation processes in membrane emulsification, Journal of Colloid and Interface Science, 2004, 279, 175.

(17) Sugiura, S., Nakajima, M., Kumazawa, N., Iwamoto, S. and Seki, M., Charaterization of spontaneous transformation-based droplet formation during microchannel emulsification, J. Phys. Chem. B., 2002, 106, 9405. 


\section{List of Tables}

Table 1 Flow conditions and dimensionless numbers during injection of dispersed phase through membrane pores 
List of Figures

Figure 1 Regular array of pores on membrane used to produce emulsions

Figure 2 Drops emerging from membrane pores and deformed from spherical shape giving rise to the push-off force

Figure 3 Effective push-off force for drops of spherical diameters of 500 to 200 microns at different pores spacings

Figure 4 Effective push-off force with spherical drop diameter at two different pore spacings: 80 and 200 microns

Figure 5 Drop size distributions obtained by laser light diffraction at different injection rates

Figure 6 Drop size with measure of spread (D90 to D10) as a function of injection rate through a 20 micron pore size membrane with 80 micron clearance between the pores

Figure 7 Drop size with measure of spread (D90 to D10) as a function of injection rate through a 20 micron pore size membrane with 200 micron clearance between the pores

Figure $8 \quad$ Variation of drop size distribution span with Weber number based on drop diameter for membrane pore sizes between 7 and 60 microns and pore spacing 80 microns

Figure 9 Variation of drop size distribution span with Weber number based on drop diameter for membrane pore sizes between 13 and 20 microns and pore spacing 200 microns

Figure 10 Comparison of predicted and measured drop sizes for membranes with pore sizes between 7 and 60 microns and pore spacings of 80 and 200 microns: with and without push-off force included 
Table 1 Flow conditions and dimensionless numbers during injection of dispersed phase through membrane pores

$\begin{array}{rrrrrr}\begin{array}{c}\text { Injection } \\ \text { rate } \\ (\mathrm{ml} / \mathrm{min})\end{array} & \begin{array}{c}\text { Velocity } \\ \text { per pore } \\ (\mathrm{cm} / \mathrm{s})\end{array} & \begin{array}{c}\text { Reynolds } \\ \text { number } \\ (-)\end{array} & \begin{array}{c}\text { Capillary } \\ \text { number } \\ (-)\end{array} & \text { Weber number } & \begin{array}{c}\text { Weber number } \\ \text { (using drop diameter }) \\ (-)\end{array} \\ 0.1 & 0.021 & 0.004 & 3.0 \mathrm{E}-05 & 1.2 \mathrm{E}-07 & 1.5 \mathrm{E}-06 \\ 0.2 & 0.041 & 0.008 & 5.9 \mathrm{E}-05 & 4.9 \mathrm{E}-07 & 6.1 \mathrm{E}-06 \\ 0.4 & 0.083 & 0.017 & 1.2 \mathrm{E}-04 & 2.0 \mathrm{E}-06 & 2.5 \mathrm{E}-05 \\ 0.5 & 0.104 & 0.021 & 1.5 \mathrm{E}-04 & 3.1 \mathrm{E}-06 & 3.8 \mathrm{E}-05 \\ 0.8 & 0.166 & 0.033 & 2.4 \mathrm{E}-04 & 7.9 \mathrm{E}-06 & 9.8 \mathrm{E}-05 \\ 1 & 0.207 & 0.041 & 3.0 \mathrm{E}-04 & 1.2 \mathrm{E}-05 & 1.5 \mathrm{E}-04 \\ 2.5 & 0.518 & 0.104 & 7.4 \mathrm{E}-04 & 7.7 \mathrm{E}-05 & 9.6 \mathrm{E}-04 \\ 5 & 1.036 & 0.207 & 1.5 \mathrm{E}-03 & 3.1 \mathrm{E}-04 & 3.8 \mathrm{E}-03 \\ 10 & 2.072 & 0.414 & 3.0 \mathrm{E}-03 & 1.2 \mathrm{E}-03 & 1.5 \mathrm{E}-02 \\ 15 & 3.108 & 0.622 & 4.4 \mathrm{E}-03 & 2.8 \mathrm{E}-03 & 3.5 \mathrm{E}-02 \\ 17.5 & 3.627 & 0.725 & 5.2 \mathrm{E}-03 & 3.8 \mathrm{E}-03 & 4.7 \mathrm{E}-02 \\ 20 & 4.145 & 0.829 & 5.9 \mathrm{E}-03 & 4.9 \mathrm{E}-03 & 6.1 \mathrm{E}-02 \\ 25 & 5.181 & 1.036 & 7.4 \mathrm{E}-03 & 7.7 \mathrm{E}-03 & 9.6 \mathrm{E}-02 \\ 30 & 6.217 & 1.243 & 8.9 \mathrm{E}-03 & 1.1 \mathrm{E}-02 & 1.4 \mathrm{E}-01\end{array}$




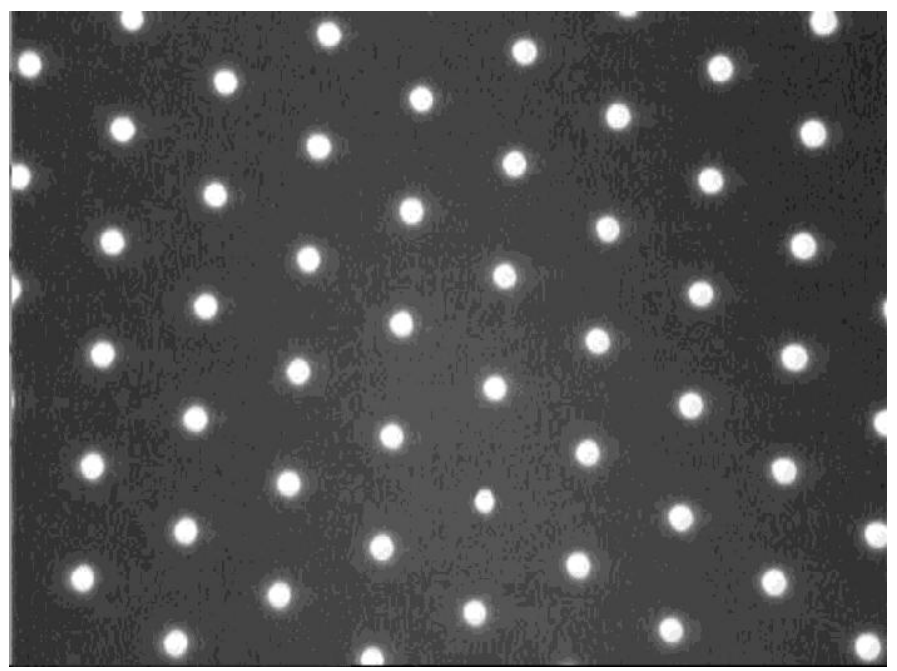

Figure 1 Regular array of pores on membrane used to produce emulsions 


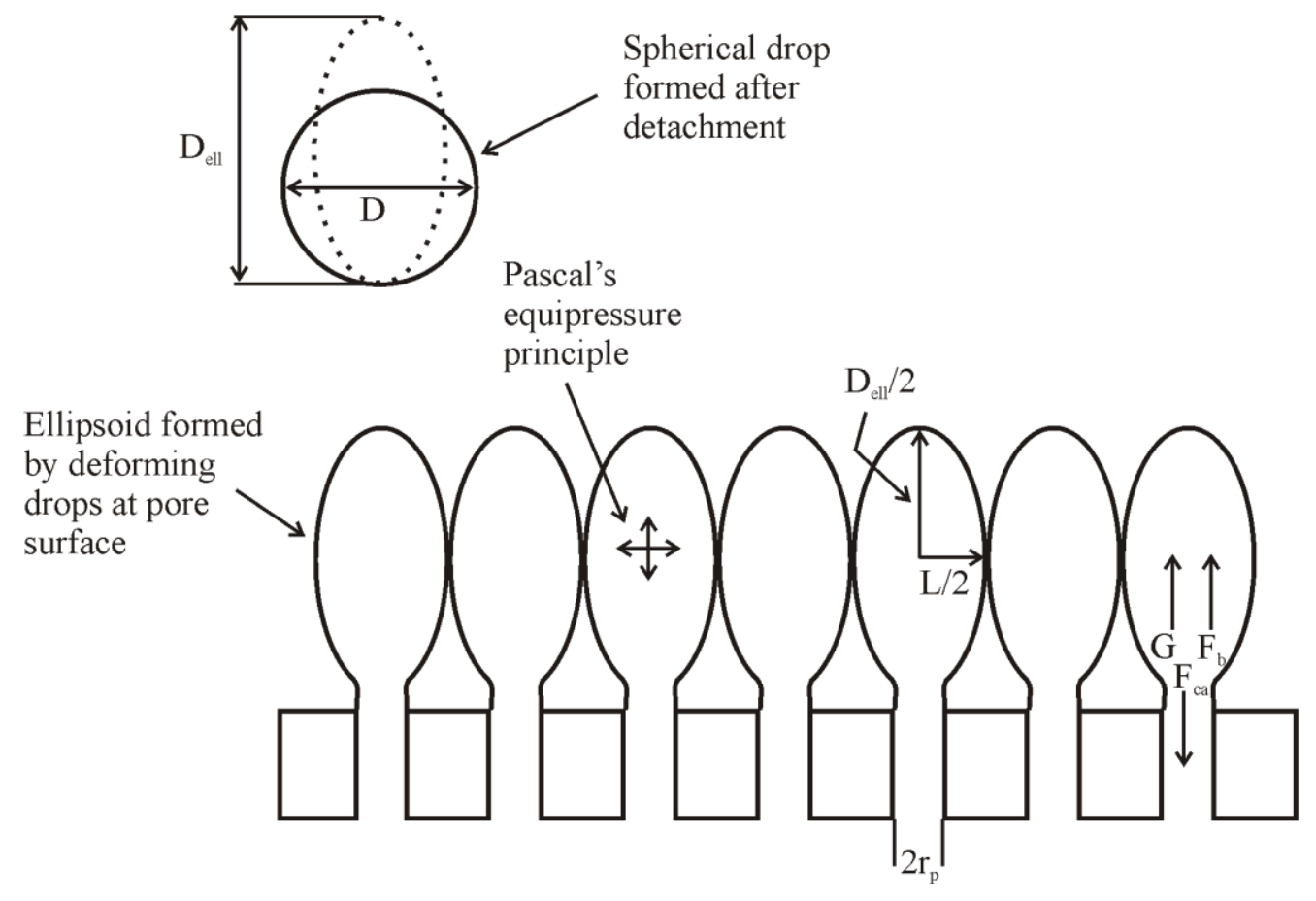

Figure 2 Drops emerging from membrane pores and deformed from spherical shape giving rise to the push-off force 


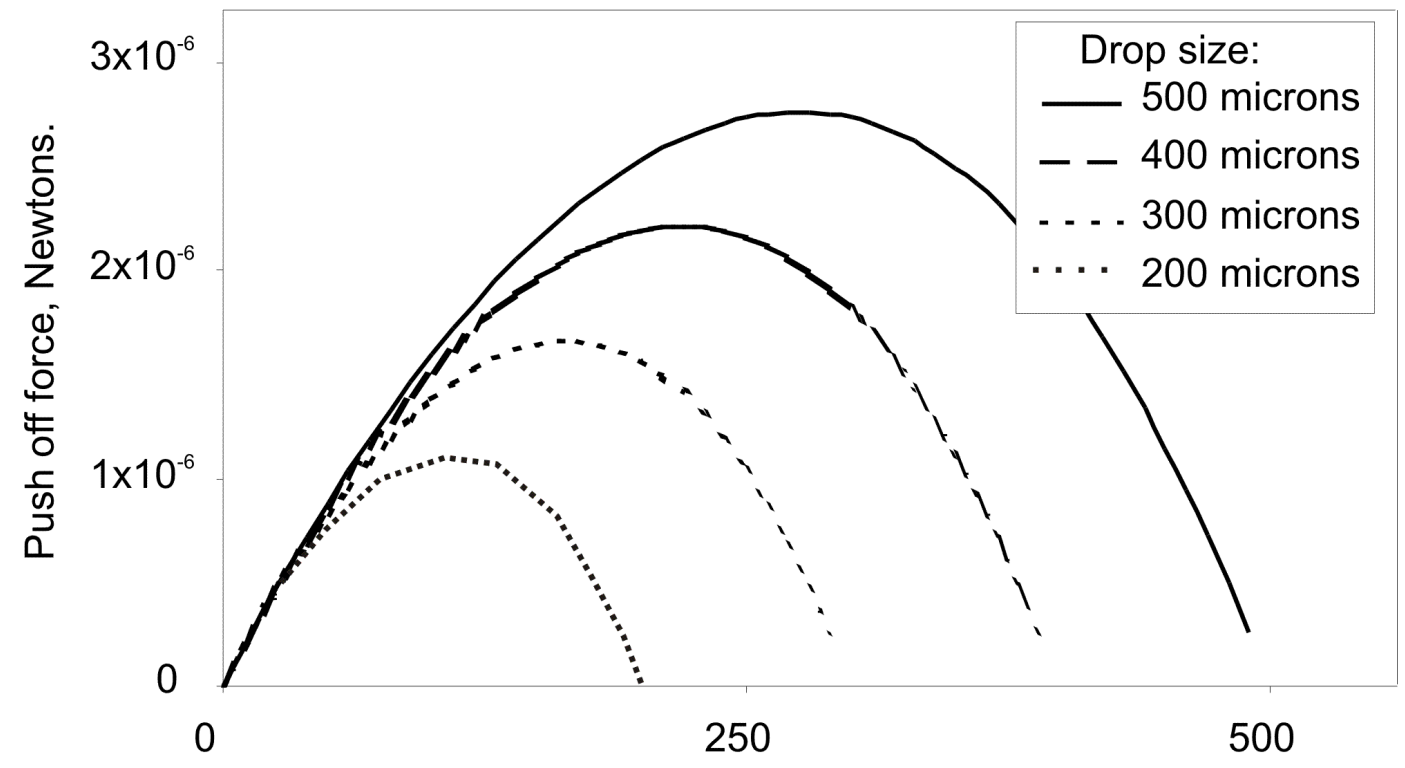

Spacing between the membrane pores, microns.

Figure 3 Effective push-off force for drops of spherical diameters of 500 to 200 microns at different pores spacings 


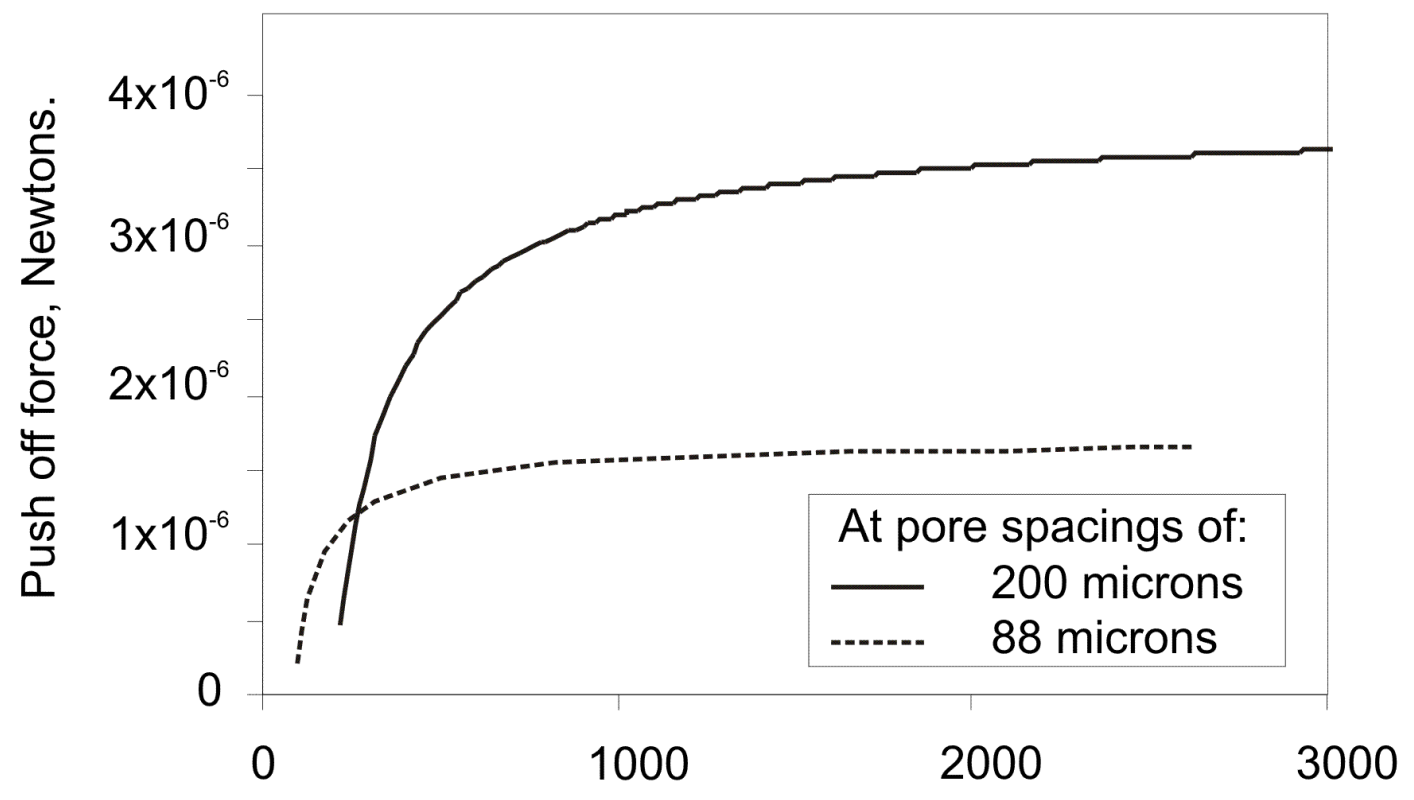

Drop diameter formed at membrane surface, microns.

Figure 4 Effective push-off force with spherical drop diameter at two different pore spacings: 80 and 200 microns 


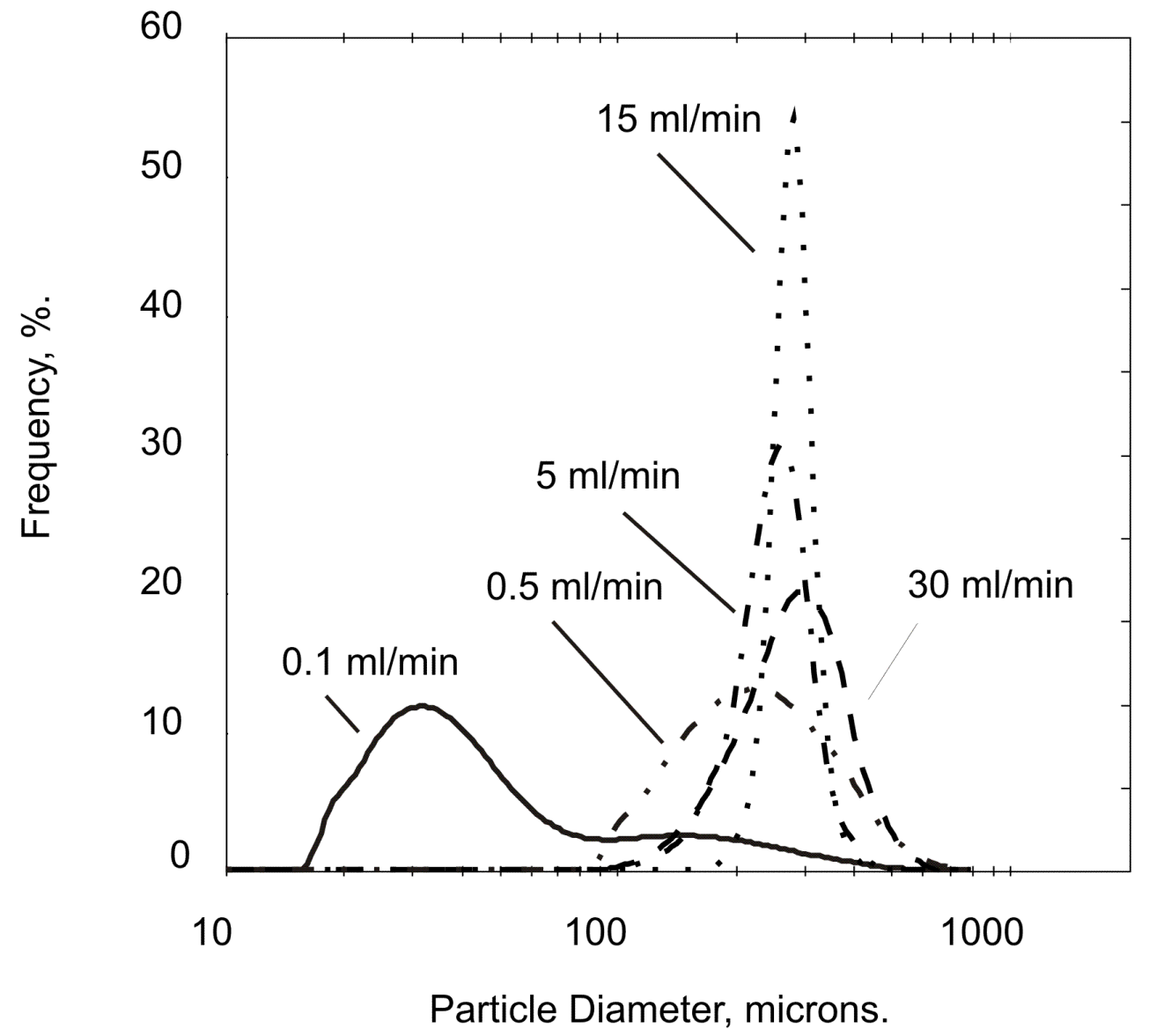

Figure 5 Drop size distributions obtained by laser light diffraction at different injection rates 


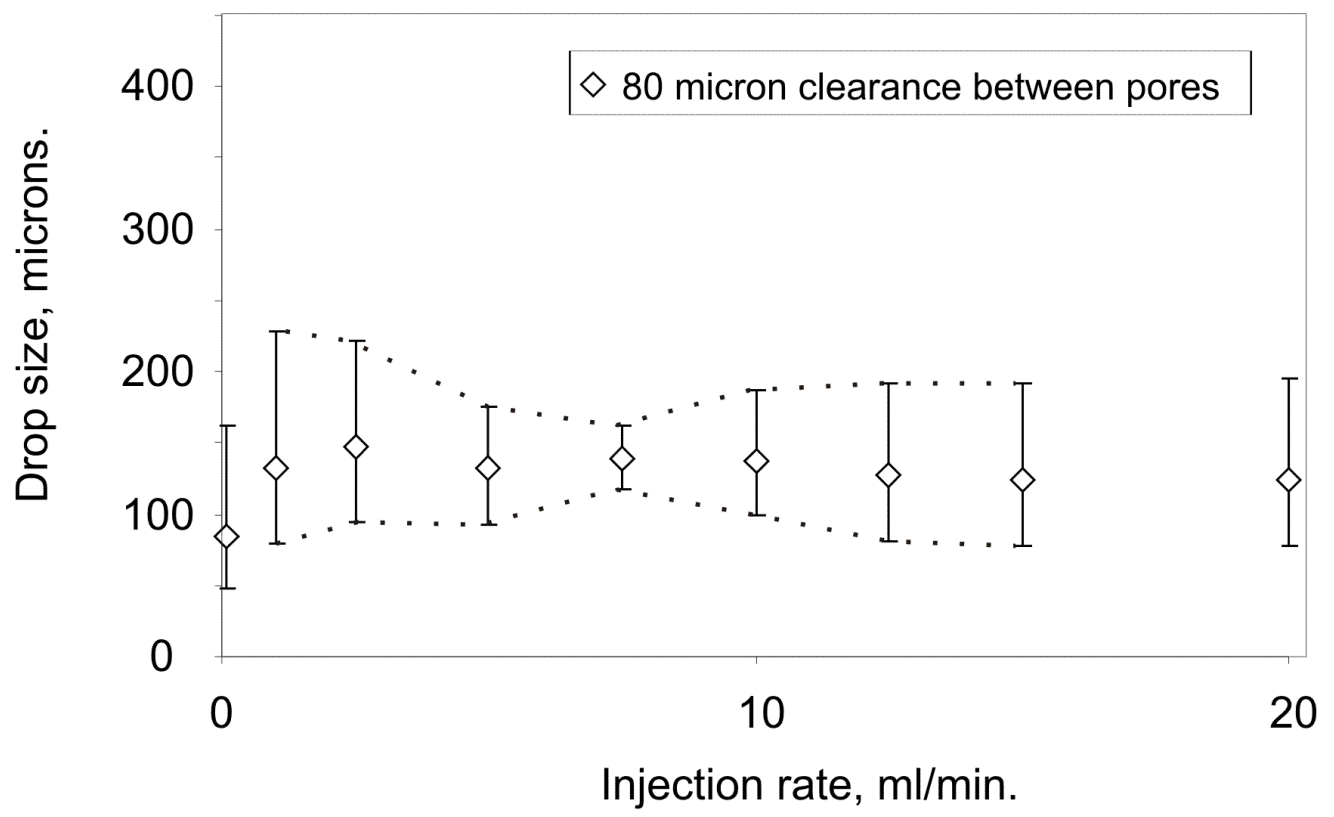

Figure 6 Drop size with measure of spread (D90 to D10) as a function of injection rate through a 20 micron pore size membrane with 80 micron clearance between the pores 


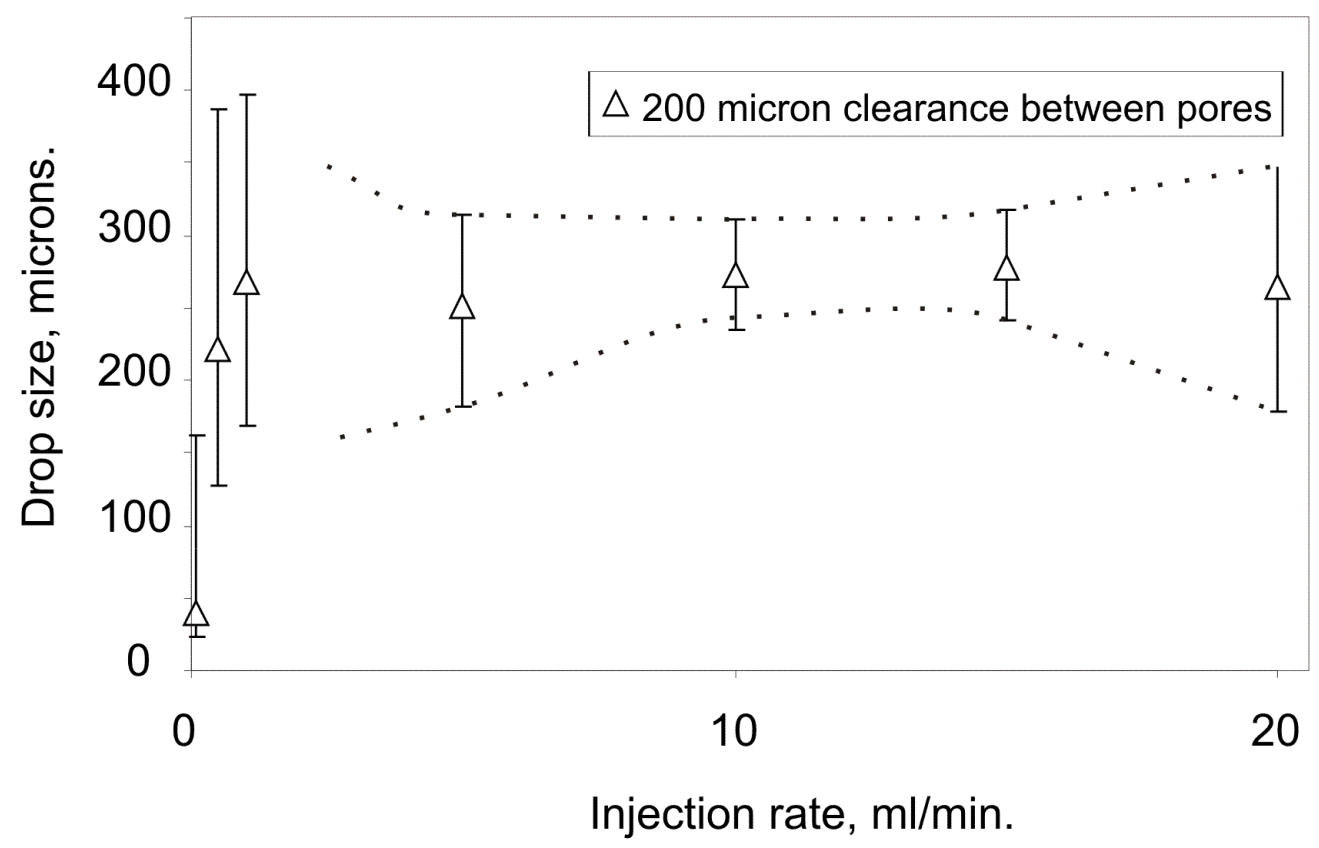

Figure 7 Drop size with measure of spread (D90 to D10) as a function of injection rate through a 20 micron pore size membrane with 200 micron clearance between the pores 


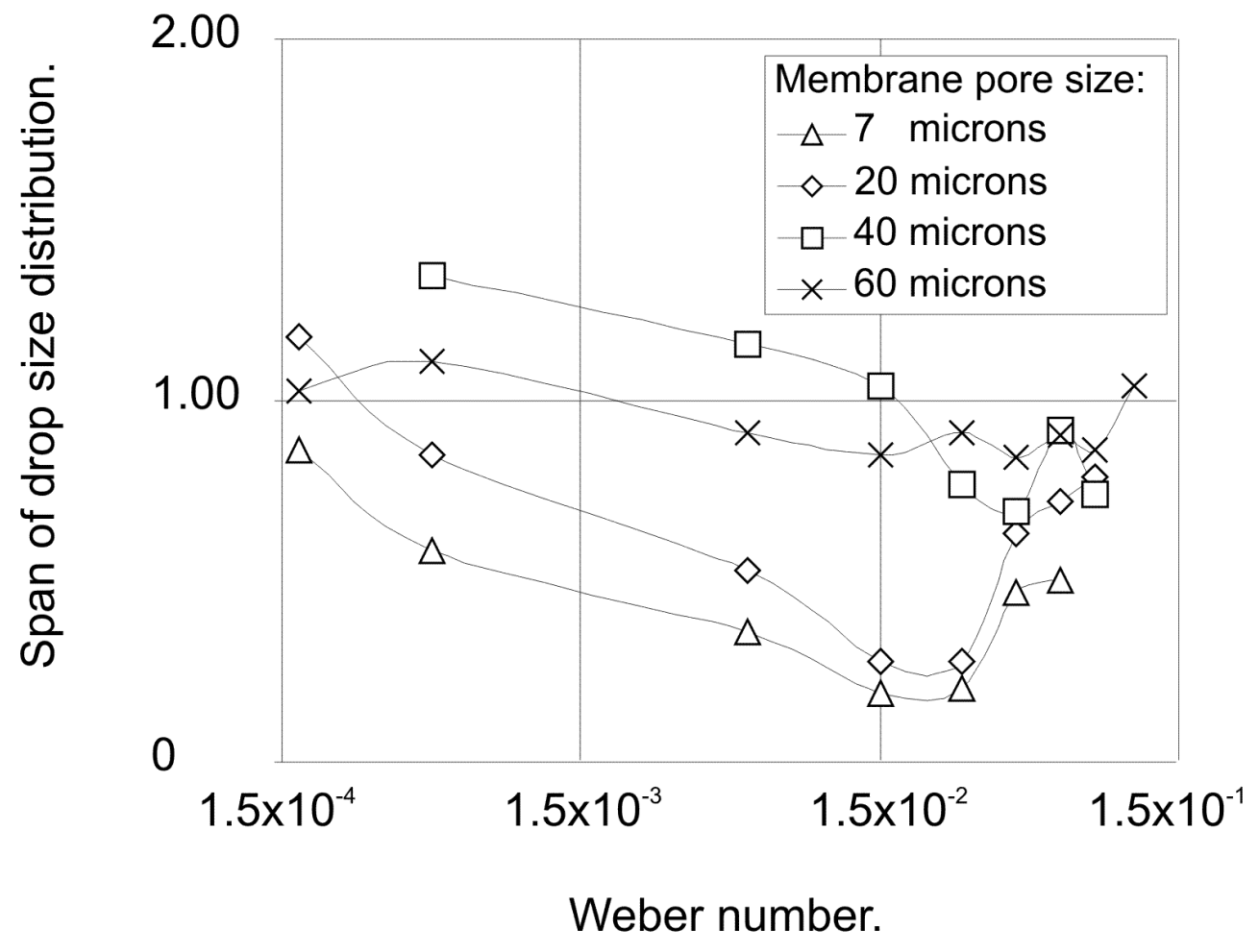

Figure 8 Variation of drop size distribution span with Weber number based on drop diameter for membrane pore sizes between 7 and 60 microns and pore spacing 80 microns 


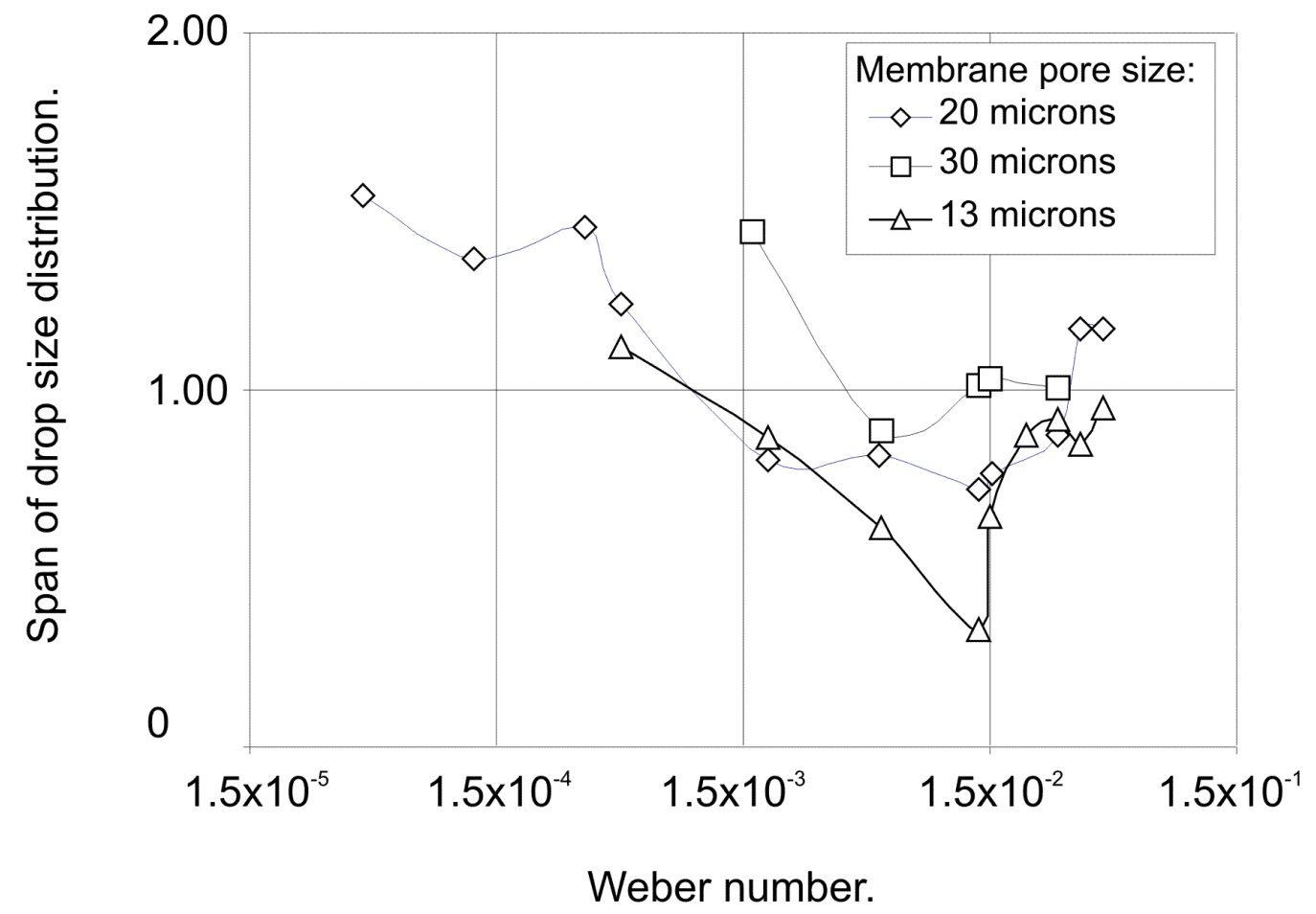

Figure 9 Variation of drop size distribution span with Weber number based on drop diameter for membrane pore sizes between 13 and 20 microns and pore spacing 200 microns 


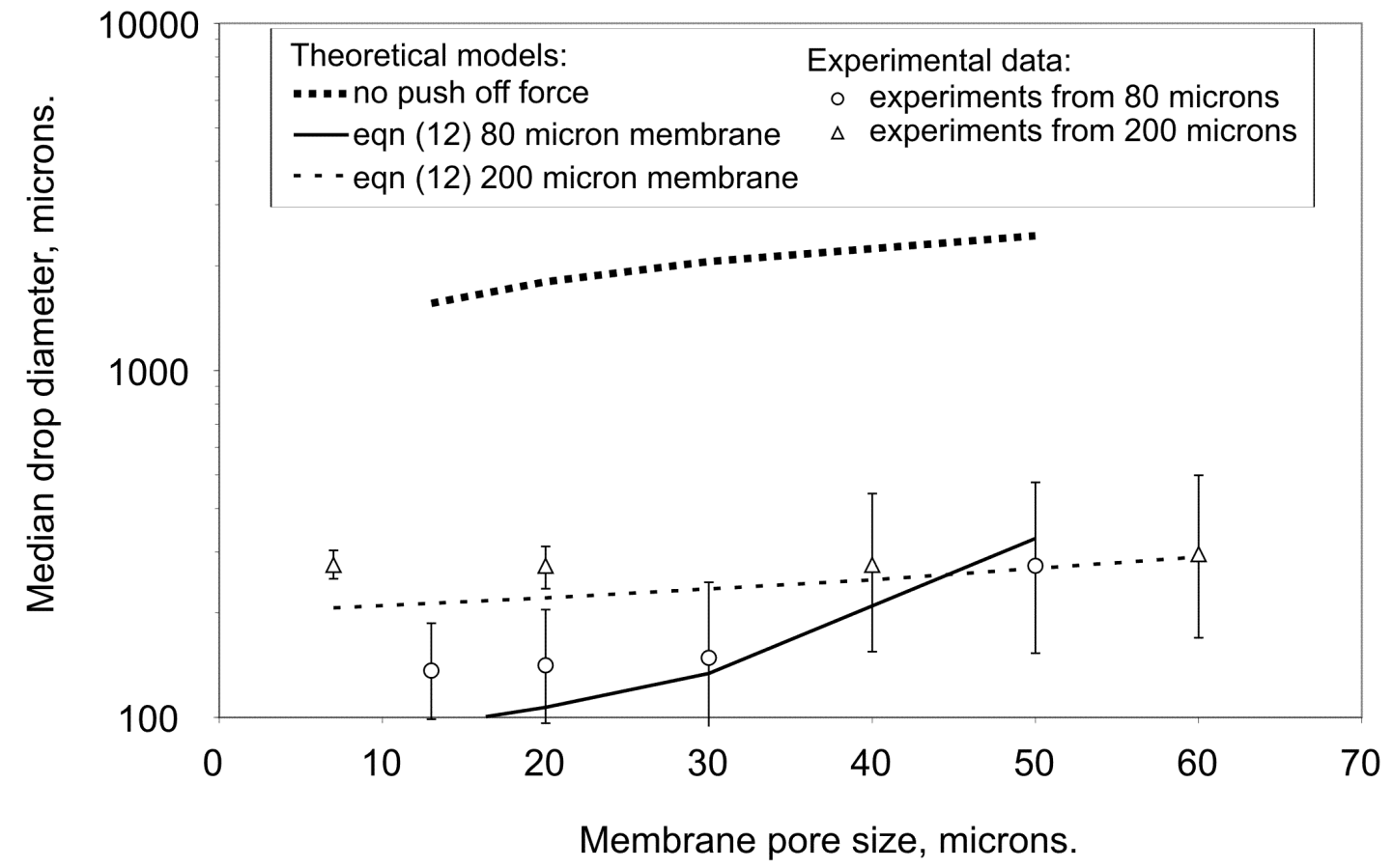

Figure 10 Comparison of predicted and measured drop sizes for membranes with pore sizes between 7 and 60 microns and pore spacings of 80 and 200 microns: with and without push-off force included 